\title{
Peculiarities of Electron-Beam Formation of Hydrophobic and Superhydrophobic Coatings Based on Hydrocarbons of Various Molecular Weights and PTFE
}

\author{
Qi Chen ${ }^{a}$, A.V. Rogachev ${ }^{a, b}$, M.A. Yarmolenko ${ }^{a, b,}{ }^{*}$, A.A. Rogachev ${ }^{a, b}$, Xiaohong Jiang ${ }^{a,{ }^{*}}$ and \\ D.L. Gorbachev ${ }^{\text {b }}$
}

anternational Chinese-Belorussian Scientific laboratory on Vacuum-Plasma Technology, College of Chemical Engineering, Nanjing University of Science and Technology, Nanjing 210094, China

${ }^{b}$ Francisk Skorina Gomel State University, 104, Sovetskaya Street, Gomel 246019, Belarus

\begin{abstract}
The paper studies the possibility of superhydrophobic coatings formations at exposure of powder mixture of polytetrafluorethylene and hydrocarbons having various molecular weights to low-energy electron beam in vacuum. It is shown that paraffin and PTFE based thin composite coatings may be characterized by superhydrophobic properties. The superhydrophobic properties are attained due to low surface energy of the fluorine-containing component and structured surface due to peculiarities of composite layer formation. The chemical processes observed in electron beam exposed area determine the molecular structure, morphology and the contact angle of thin organic coatings deposited. It is shown that high-molecular-weight hydrocarbon compounds should not be recommended for vacuum electron-beam deposition of superhydrophobic thin coatings because of deep changes in the molecular structure exposed to electron beam. These processes are responsible for high degree of unsaturation of the thin layer formed and for occurrence of oxygen-containing polar groups. The influence of substrate temperature on molecular structure, morphology and hydrophobic properties of thin coatings deposited is investigated. Potentially such coatings may be applied for deposition on the surface of metal capillaries used in biotechnological analyzers.
\end{abstract}

Received on 31-10-2016 Accepted on 07-12-2016

Published on 14-06-2017

Keywords: Electron-beam deposition, superhydrophobic coatings, paraffin, polytetrafluorethylene, molecular structure, nanocomposite coatings.

\section{INTRODUCTION}

If the contact angle of a solid surface exceeds $150^{\circ}$, such surface is called superhydrophobic [1, 2]. The superhydrophobic properties are used in various industrial and biological applications [3, 4]. Two methods are used in production of superhydrophobic surfaces: 1) creation of hierarchical structures (micro- and nanostructures) on hydrophobic substrates, and 2) chemical modification of hierarchical structured surfaces for the purpose of contributing low surface energy to them [1, 2]. The surfaces characterized by superhydrophobic properties may be obtained by means of self-assembly [5], phase separation [6], sol gel technique [7, 8], electrical deposition [9], anodization $[10,11]$, chemical vapor deposition [12], physical vacuum deposition [13, 14], using aerosols [15] and patterns [16], as well as combination of various methods $[17,18]$.

"International Chinese-Belorussian Scientific laboratory on Vacuum-Plasma Technology, College of Chemical Engineering, Nanjing University of Science and Technology, Nanjing 210094, China; Tel: +375 232 578253;

Fax: +375 232 578253; E-mail: simmak79@mail.ru

Tel: +86 25 84315943; Fax: +86 25 84315585; E-mail: jxh0668@sina.com
The main disadvantage of most methods is presence of multiphase process, need for liquid media and high temperature, impossibility to form thin $(<1 \mu \mathrm{m})$ coatings. Vacuum sputtering methods are characterized by low deposition rate, complexity of deposition process control systems and dielectric substrates processing. The impact of high-energy charged particles on organic substrates may be followed by irreversible chemical processes (cross-linking, destruction). Such processes are followed by changes in physical and chemical properties of the substrates, which are inacceptable in some cases (e.g., medical polymer implants). It should be emphasized that the above methods cannot be effectively used for coating formation on final products or conferring a complex of properties upon the surface, in particular, superhydrophobic and antibacterial ones.

The method of electron-beam forming of polymer coatings is devoid of most of the mentioned disadvantages. It makes it possible to deposit the coatings of complex composition and structure onto the finished products using technologically simple equipment $[19,20]$. Any material may serve as a 
substrate of complex shape: paper, polymer films, metal, etc. The deposition of the coatings is not followed by changes in linear dimensions and heating of the substrates. The exposure of polymer materials to low-energy electron beam in vacuum is followed by formation of thin layers based on various macromolecular compounds, polytetrafluorethylene (PTFE) [21] in particular. The PTFE-based coatings are characterized by low surface energy, which allows using them as hydrophobic and antifriction layers [21, 22]. The smoothed morphology of thin fluoroplastic layer is one of the causes for the lack of superhydrophobic properties of the layers formed: the water contact angle in most cases does not exceed $130^{\circ}$.

The main objective of the present study was to ascertain the possibilities and peculiarities of superhydrophobic coatings based on hydrocarbons and polytetrafluorethylene formed by electron-beam method. It was suggested to use polytetrafluorethylene and hydrocarbons of various molecular weights as the components of hydrophobic coatings formed. The superhydrophobic properties were to be achieved due to the low surface energy of a fluorine-containing component and a structured surface due to the peculiarities of the composite layer structure formation. The microroughness control was planned to be carried out by changing the substrate temperature during the coating deposition. The temperature corresponding to the melting point of the hydrocarbon component should result in formation of hydrocarbon microdroplets in an inert fluoroplastic matrix.

For attaining the goal it was necessary to solve a number of problems: to identify the impact of the nature and the ratio of the components on peculiarities of the chemical reactions observed in electron beam impact zone, the impact of the mentioned chemical processes, as well as the substrate temperature, on molecular structure, morphology and hydrophobic properties of thin coatings deposited.

The paper is scientifically and practically oriented. Scientific interest was in the study of the peculiarities of structure

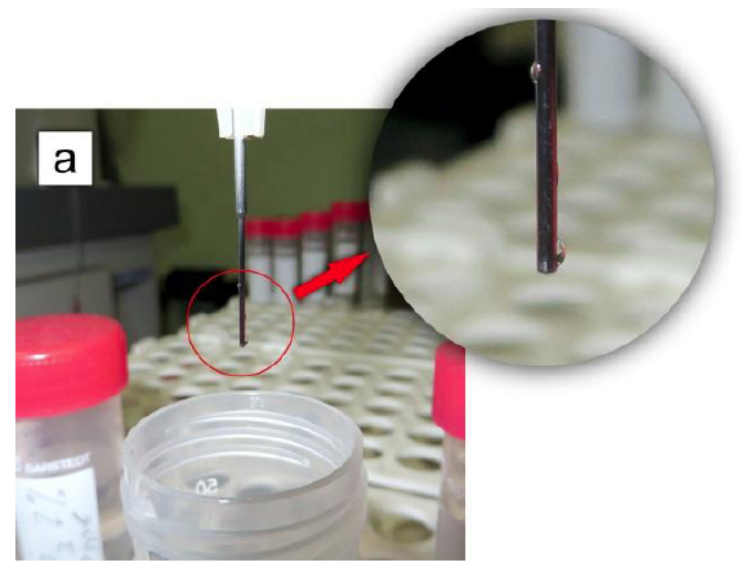

formation in thin-film systems based on thermodynamically incompatible compounds (hydrocarbons and fluoroplastic), the formation of which otherwise is virtually impossible. On the other hand, the reason for the study is to search for effective and economical ways of conferring superhydrophobic properties upon thin metal capillaries used in biological analyzers to transfer various liquids from test tubes. In the capillaries operation, the formation of working liquid droplets at the tip of the capillaries is unacceptable. It results in test integrity disruption (Figure 1).

\section{METHODOLOGY OF THE EXPERIMENT}

\subsection{Surface Deposition}

The surfaces were formed from the active gas phase generated at exposure of the target material to the lowenergy electron beam of $800 \sim 1600 \mathrm{eV}$ energy and $0.01 \sim$ $0.03 \mathrm{~A} / \mathrm{cm}^{2}$ density [19]. The initial pressure of the residual gas in the vacuum chamber was $4 \times 10^{-3} \mathrm{~Pa}$. The growth rate $(\mathrm{Hz} / \mathrm{s})$ in the deposition process was monitored with quartz crystal microbalance (QCM). It should be noted that we did not convert the quartz meter readings in ton $\mathrm{m} / \mathrm{s}$. This is due to the fact that such conversion requires the data on the density of the deposited layer. The density of the coating is marked by complex dependence on multiple technological deposition parameters, the duration of the electron beam impact and may differ significantly from the density of the initial polymer. Currently, there are no reliable methods to determine the density of such thin-film systems. Thus, for preliminary studies, we consider using $\mathrm{Hz}$ values instead of $\mathrm{nm}$ ones to be well grounded.

\subsection{Material Description}

The following substances were used as target materials: lowdensity polyethylene (LDPE, medium molecular weight $\mathrm{Mw}=$ 261530, Mw/Mn = 15.49; density = $0.92 \mathrm{~g} / \mathrm{cm}^{-3}$ ), ultrahighmolecular-weight polyethylene (UHMW PE, Mw $=5 \cdot 10^{6}$; density $=0.93 \mathrm{~g} / \mathrm{cm}^{-3}$, Foresight Global FZE), paraffin,

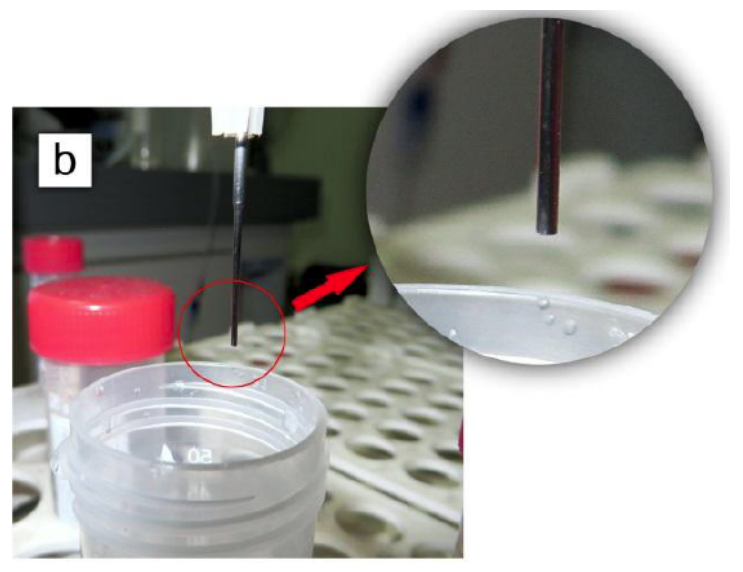

Figure 1: Capillaries used in a biological analyzer.

a - non-modified capillary; $\mathbf{b}$ - capillary coated with paraffin - PTFE $(1: 6)$ at $50^{\circ} \mathrm{C}$. 
polytetrafluorethylene (PTFE, density $=2.15 \mathrm{~g} / \mathrm{cm}^{-3}$, Aldrich). The powders were not additionally dried before application.

The formation of composite surfaces was implemented by using mixtures of hydrocarbon and polytetrafluorethylene powders in 1:1, 1:2, 1:4, 1:6 weight ratios. The reaction activity of volatile products of dispersion was evaluated according to the value of $R=V / P$ (where $V$ is thin layer deposition rate $(\mathrm{Hz} / \mathrm{s}), \mathrm{P}$ is the pressure of volatile products of dispersion $(\mathrm{Pa})$ ).

The coating deposition was implemented on substrates with surface temperature of $25^{\circ} \mathrm{C}$ (room temperature) and $50^{\circ} \mathrm{C}$ (for paraffin), as well as $25^{\circ} \mathrm{C}$ and $120^{\circ} \mathrm{C}$ (LDPE, UHMW PE). The substrates were heated to various temperatures and placed side by side in order to deposit layers of the same thickness on them. High temperature of the substrate was corresponding to the melting point of the hydrocarbon compound. The depressurization of the vacuum chamber was done after rising the substrate temperature to room temperature.

The dispersion of all the targets used in the work was continued up to the moment of virtually complete cessation of the gas phase generation (transfer of the entire target volume into gas phase). It was done to decrease the impact of difference in dispersion rates of individual components of the target on average composition of the coating deposited.

Only the coatings with the same QCM-defined effective thickness were analyzed.

Silicon single crystal wafers (100) were used as the substrates during microscopy, X-ray photoelectron spectroscopy (XPS) and measuring of the contact angle, and sodium chloride during IR analysis.

The chemical compound of the deposited layers was studied with XPS. Using XPS made it possible to identify the impact of chemical reactions initialized by the electron beam in the target on the chemical compound of the deposited thin layer. The measurements were made by spectrometer $\mathrm{PHI}$ Quantera II Scanning XPS Microprobe, using the source Al $\mathrm{Ka}$ of monochromatic X-radiation $(h v=1486.6 \mathrm{eV})$. The results of the analysis were processed in Mathcad software system. The percentage of the coatings was calculated due to the ratio of peak areas obtained during decomposition.

The analysis of molecular structure of the coatings formed was performed by means of IR-Fourier spectrophotometer Vertex-70 (Bruker). The scanning was made in $4000-$ $300 \mathrm{~cm}^{-1}$ range with $4 \mathrm{~cm}^{-1}$ resolution. The spectra of hydrocarbon coatings were rated to the $\delta$ band $(\mathrm{C}-\mathrm{H})$ at 1465 $\mathrm{cm}^{-1}$ (in-house standard). Hydrocarbon materials crystallinity measurement was carried out using absorption bands intensities ratio at 730 and $720 \mathrm{~cm}^{-1}$ or 1470 and $1465 \mathrm{~cm}^{-1}$ [23]. The bands intensity at 730 and $720 \mathrm{~cm}^{-1}$ is mostly determined by orientation of the thin layer. Therefore, in the present study, 1470/1465 absorption bands intensities ratio was used to determine the crystallinity (degree of order) of thin coatings. The short chain branching was evaluated by the ratio of the optical density of deformation vibrations band of $\mathrm{C}-\mathrm{H}$ bonds in $\mathrm{CH}_{3}\left(1378 \mathrm{~cm}^{-1}\right)$ to the optical density of the in-house standard band. In IR spectrum, the PTFE absorption at $625 \mathrm{~cm}^{-1}$ is associated with the presence of a defect structure formed as a result of thermal exposure, and at 640 $\mathrm{cm}^{-1}$ it is associated with the presence of a regular molecule helix [24]. To determine the degree of deficiency of the coating fluorine-containing component, the intensities ratio of $640 / 625$ bands was used.

The cross-section morphology of the coatings was studied with scanning electron microscopy (SEM Quanta $200 \mathrm{~F}$ ).

The coatings wetting was evaluated by measuring the static contact angle. The static contact angles were obtained using the Krüss DSA 100 goniometer. A drop of distilled water $(5 \mu l)$ was deposited onto the coating surface. The period between the coating deposition and the measurement of the contact angle was as long as 1 week. For each sample at least 10 droplets were measured. The measurements error was $\pm 2^{\circ}$.

The hysteresis of the contact angle was measured for the coatings with superhydrophobic properties. The dynamic measurements were done by increasing the drop volume from $2 \mu \mathrm{l}$ to $15 \mu \mathrm{l}$ at a rate of $30 \mu \mathrm{l} / \mathrm{min}$, which allowed measuring the advancing contact angle. Then the drop volume was decreased back to $2 \mu \mathrm{l}$ at the same rate, which made it possible to measure the receding angle. The measurements were performed each second of increases and decreases in the drop volume.

\section{RESULTS AND DISCUSSION}

\subsection{Features of Electron Beam Target Dispersion}

A characteristic property of polyethylene targets dispersion with the electron beam as compared to paraffin dispersion is significantly higher pressures of the volatile products generated and their significantly lower reactivity (Table 1 ). The high pressure at low deposition rate is observed in case of significant content of low-molecular weight compounds in gas phase, which are characterized by low ability to condense on the substrate at room temperature.

The properties described may be explained by the difference in the properties of hydrocarbon melts. A rapid melting of the hydrocarbon target occurs at exposure to electron beam. The major part of the electron beam energy, when dispersing the polymer melt, is released at a certain depth from the surface [25]. In the near-surface region of the melt, a significant amount of hydrocarbon molecules destruction fragments is formed. Being diffused through the melt, they form the gas phase. The higher the melt viscosity, the longer the destruction fragment resides in the melt under the impact of electron beam. Chemical interactions in the melt affect the 
molecular weight and the chemical activity of the hydrocarbon fragments forming the gas phase, in particular, they may lead to their decrease.

For composite targets, non-monotonous change in growth rate and pressure is characteristic at the increase in PTFE mass content in the target dispersed. The increase in PTFE mass content in the target prevents the formation of the hydrocarbon component melt. At the components ratio of $1: 1$ in the target, hydrocarbon melting only occurs on individual areas of the surface. At a higher content of PTFE in the target, it is impossible to visually capture the formation of hydrocarbon component melt in the target. The impact of an electron beam on the composite target leads to rapid formation of black carbonized layer on its surface. The target carbonization indicates the chemical interaction between hydrogen- and fluorine-containing destruction products. This interaction may result in decrease in chemical activity of the destruction products.

Thus, the impact of electron beam initiates deep processes of destruction of hydrocarbon macromolecules. For highmolecular-weight compounds, these processes are the most pronounced ones as compared to paraffin. The hydrocarbon fragments formed under the impact of electron beam are subject to further destruction in the process of chemical interaction with fluorine-containing PTFE dispersion products.

\subsection{IR-Spectroscopic Analysis}

The results of spectroscopic analysis of the coatings obtained are presented in Table 2 and Figure 2. In initial paraffin, the main type of unsaturation is vinylidene $\left(>\mathrm{C}=\mathrm{CH}_{2}, 888 \mathrm{~cm}^{-1}\right)$ one. As for vinylidene groups in the deposited thin layer, their content is significantly lower than in initial paraffin. The main type of unsaturation of molecular structure of the deposited coating is trans-vinylene $\left(-\mathrm{CH}=\mathrm{CH}-, 965 \mathrm{~cm}^{-1}\right)$ one. The high content of trans-vinylene bonds is also peculiar to the target material after dispersion. The results are predictable. Electron-beam impact on hydrocarbon chain leads to its destruction with the appearance of free radicals. The migration of free radicals on the carbon chain and their subsequent interaction with each other are followed by formation of trans-vinylenebonds [23]. The decrease in vinylydeneun saturation is due to intense destruction of chains close to this type of unsaturation.

The molecular structure of the coating based on UHMW PE is very much different from the molecular structure of initial polymer. In the structure of the thin layer there are short chain branching, trans-vinylene and vinyl groups $\left(-\mathrm{C}=\mathrm{CH}_{2}\right.$, $908 \mathrm{~cm}^{-1}$ ), which are absent in the structure of UHMW PE. It is important to note that the content of double unsaturated bonds and short chain branching in the target material after dispersing of the polymers is significantly higher than in thin coatings formed.

The molecular structure of the coatings based on PE, in comparison with initial polymer, is also more unsaturated. In addition, the content of short chain branching in the structure of the thin layer is significantly lower. As well as for the rest of hydrocarbons, the target material after dispersion is characterized by high content of unsaturated bonds and short chain branching.

The targets analysis shows the intensive chemical reactions (cross-linking, destruction) that occur in the area of direct influence of the electron beam on the target. The fragments are products of electron-beam disperse not of initial compound, but the compounds formed as a result of the chemical reactions mentioned transfer into the gas phase. For paraffin, the reactions of hydrocarbon fragments in the dispersion zone are not as distinct as for polymers. The differences may be due to different viscosity of the melts formed.

Table 1: Parameters of Electron Beam Dispersion of Hydrocarbon and Fluorine-Containing Targets

\begin{tabular}{|c|c|c|c|c|c|c|}
\hline \multirow{2}{*}{ Deposition parameters } & \multicolumn{6}{|c|}{ weight ration of components in the mixture } \\
\hline & 1:0 & $1: 1$ & $1: 2$ & 1:4 & 1:6 & $0: 1$ \\
\hline \multicolumn{7}{|c|}{ Paraffin:PTFE } \\
\hline $\mathrm{V}, \mathrm{Hz} / \mathrm{s}$ & 520.5 & 412.9 & 223.1 & 39.1 & 108 & 111.4 \\
\hline$P_{\max },(P a)$ & 0.019 & 0.021 & 0.015 & 0.010 & 0.015 & 0.06 \\
\hline $\mathrm{R}, \mathrm{Hz} /(\mathrm{s} \mathrm{Pa}) \times 10^{-3}$ & 27.4 & 19.7 & 14.9 & 3.9 & 7.2 & 1.8 \\
\hline \multicolumn{6}{|c|}{ PE:PTFE } & \\
\hline $\mathrm{V}, \mathrm{Hz} / \mathrm{s}$ & 650.6 & 851.3 & 887.8 & 374.0 & 423.0 & \\
\hline$P_{\max },(\mathrm{Pa})$ & 0.077 & 0.127 & 0.144 & 0.122 & 0.098 & \\
\hline $\mathrm{R}, \mathrm{Hz} /(\mathrm{s} \mathrm{Pa}) \times 10^{-3}$ & 8.4 & 6.7 & 6.2 & 3.1 & 4.3 & \\
\hline \multicolumn{6}{|c|}{ UHMW PE:PTFE } & \\
\hline $\mathrm{V}, \mathrm{Hz} / \mathrm{s}$ & 341.9 & 198.0 & 549.2 & 505.7 & 439.8 & \\
\hline$P_{\max ,}(\mathrm{Pa})$ & 0.058 & 0.065 & 0.125 & 0.117 & 0.092 & \\
\hline $\mathrm{R}, \mathrm{Hz} /(\mathrm{s} \mathrm{Pa}) \times 10^{-3}$ & 5.9 & 3.1 & 4.4 & 4.3 & 4.8 & \\
\hline
\end{tabular}


Table 2: Results of IR-Spectroscopic Analysis

\begin{tabular}{|c|c|c|c|c|c|}
\hline \multirow{2}{*}{ Sample } & \multicolumn{5}{|c|}{ Frequency, $\mathrm{cm}^{-1}$} \\
\hline & $1470 / 1465$ & 888 & 965 & 908 & 1377 \\
\hline \multicolumn{6}{|c|}{ initial compounds } \\
\hline Paraffin $(P-2)$, initial & 0.89 & 0.099 & - & - & 0.260 \\
\hline Film PE $\left(120^{\circ} \mathrm{C}\right)$ & 0.61 & 0.012 & 0.001 & 0.003 & 0.105 \\
\hline Film UHMW PE $\left(120^{\circ} \mathrm{C}\right)$ & 0.95 & - & - & 0.002 & - \\
\hline \multicolumn{6}{|c|}{ target material } \\
\hline Paraffin $(P-2)$ & 0.56 & 0.071 & 0.049 & - & 0.166 \\
\hline $\mathrm{PE}$ & - & 0.123 & 0.096 & 0.306 & 0.418 \\
\hline UHMW PE & - & 0.101 & 0.154 & 1.084 & 0.780 \\
\hline \multicolumn{6}{|c|}{ coatings } \\
\hline Paraffin $\left(25^{\circ} \mathrm{C}\right)$ & 0.80 & 0.023 & 0.031 & 0.003 & 0.084 \\
\hline Paraffin $\left(50^{\circ} \mathrm{C}\right)$ & 0.71 & 0.017 & 0.053 & 0.003 & 0.108 \\
\hline $\operatorname{PE}\left(25^{\circ} \mathrm{C}\right)$ & 0.68 & 0.025 & 0.051 & 0.148 & 0.089 \\
\hline $\mathrm{PE}\left(120^{\circ} \mathrm{C}\right)$ & 0.53 & 0.029 & 0.049 & 0.135 & 0.076 \\
\hline UHMW PE $\left(25^{\circ} \mathrm{C}\right)$ & 0.83 & 0.012 & 0.056 & 0.153 & 0.050 \\
\hline UHMW PE $\left(120^{\circ} \mathrm{C}\right)$ & 0.65 & 0.016 & 0.067 & 0.195 & 0.056 \\
\hline \multicolumn{6}{|c|}{$640 / 625$} \\
\hline PTFE $25^{\circ} \mathrm{C}$ & \multicolumn{5}{|c|}{1.347} \\
\hline PTFE $50^{\circ} \mathrm{C}$ & \multicolumn{5}{|c|}{1.343} \\
\hline
\end{tabular}

Increase in substrate temperature at deposition contributes to decrease in crystallinity of hydrocarbon layers and, as a rule, to increase in content of double unsaturated bonds. These processes are due to the impact of the temperature on adsorption activity of hydrocarbon fragments characterized by high content of free radicals. The coating based on paraffin is characterized by the lowest content of double bonds.

The IR spectrum of composite coatings is presented by all the absorption bands peculiar to hydrocarbon and fluorocarbon components. The appearance of other bands was not detected. At first approximation, composite coatings may be regarded as fine-grained mechanical mixtures of modified initial components.

Mass concentration of PTFE in the target does not virtually influence on molecular structure of the paraffin component of the coating (Figure 2). The hydrocarbon component of the composite layer contains significantly lower amount of unsaturated bonds and is characterized by higher crystallinity as compared to the single-component paraffin layer. The chemical interaction of fluorine- and hydrogen-containing fragments may contribute to the growth of unsaturated bonds in thin layer, in particular, trans-vinylene one. Simultaneous deposition of fragments of various nature on the coating leads to significant decrease in deficiency of the fluorinecontaining component. It may be assumed that the chemical interaction of the components in the target with defective fluorine-containing fragments formed decreases their ability to condense on the substrate and form a thin layer. On the other hand, the lack of the melt contributes to intensity decrease of chemical interactions between hydrocarbons in the dispersion zone, which affects the degree of order and unsaturation of hydrocarbon component. High temperature of the substrate decreases the crystallinity of the paraffin component and increases the degree of deficiency of the fluorine-containing component of the composite coating.

Use of PTFE when depositing the composite layer based on polymers reduces vinyl unsaturation, the degree of order and slightly increases the growth of trans-vinylene groups in hydrocarbon component as compared with the correspondent single-component coating. The result is predictable. Vinyl groups are located at the ends of hydrocarbon chains with increased mobility. This causes their higher chemical activity in the dispersion zone, in particular, in interaction with fluorine-containing fragments. Growth of trans-vinyl unsaturation and decrease in the degree of order of the coating's hydrocarbon component may be a result of chemical interaction of dispersion products.

The highest degree of defectiveness of the composite layer's fluorine-containing component was detected while using UHMW PE. The result may be due to intense chemical interactions between the formed hydrocarbon and fluorinecontaining polymer dispersion products. The formation of chemically reactive hydrocarbon fragments is indirectly confirmed by the above mentioned significant differences in the molecular structure of the coating from that of the initial polymer. 


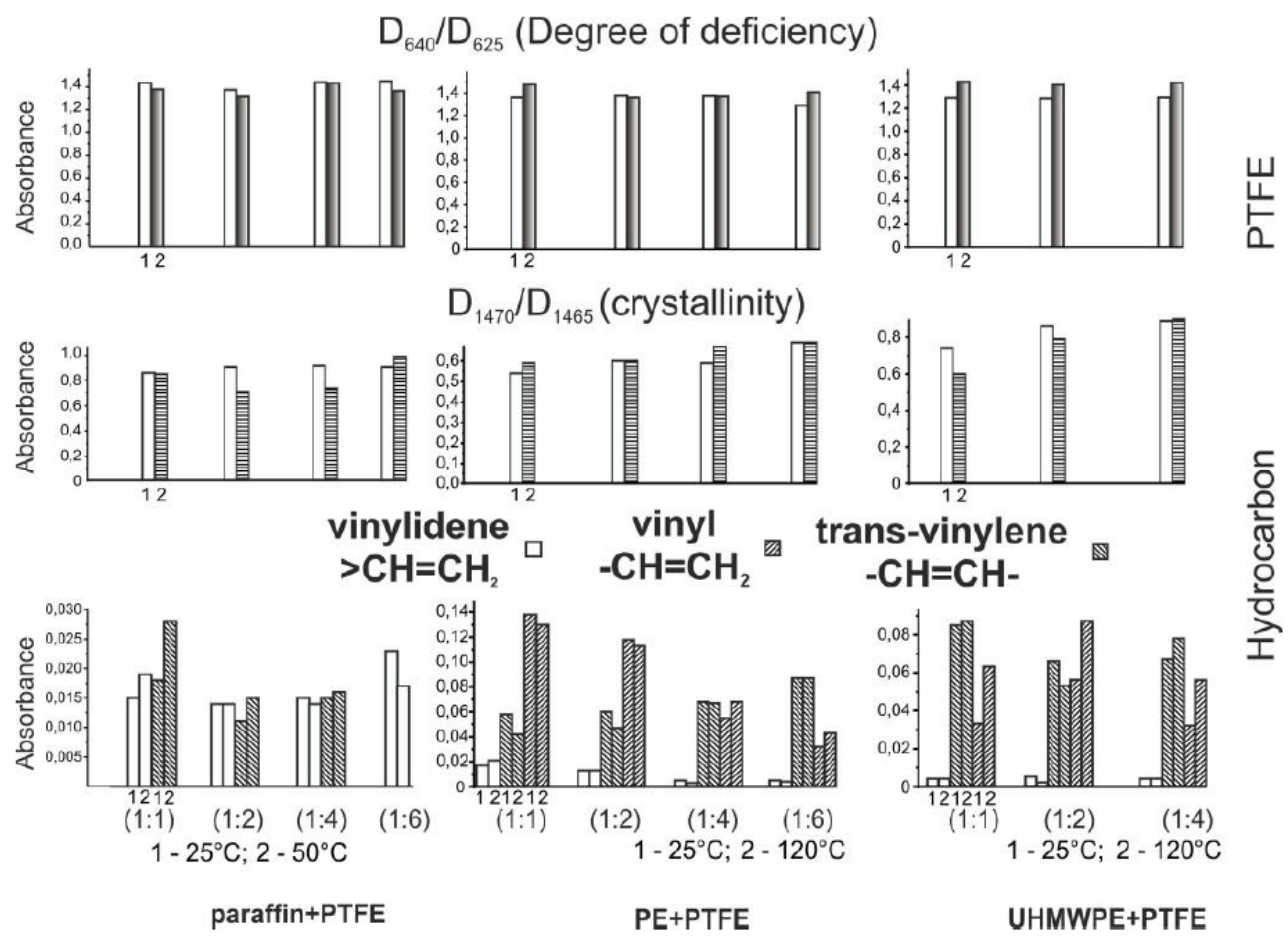

Figure 2: Results of IR spectroscopic analysis.

The IR spectroscopic analysis data is in full agreement with the results of studies of electron-beam dispersion of various targets. It was previously shown that for high-molecularweight hydrocarbon compounds the molecules destruction process under the impact of electron flow are much more pronounced as compared to paraffin. This exactly explains the high content of the formed thin layers of double unsaturated bonds in the molecular structure.

\subsection{XPS Analysis}

The chemical composition of thin coatings was studied with X-ray photoelectron spectroscopy (XPS) (Figure 3).

C1s spectra were analyzed in accordance with recommendations presented in $[26,27]$. The chemical composition of the coating formed by electron beam exposure of PTFE powder is mainly presented by atoms of fluorine of carbon. The value of the ratio $F / C$ is 1.99 . The exposure of electron beam on PTFE is not followed by significant defluorination of fluorocarbon molecules that form the polymer layer. Apart from six low-intensity peaks, C1s spectrum is formed by two main ones - $\left(-\left(\mathrm{CF}_{2}-\mathrm{CF}_{2}\right)-\right)$ at $291.6 \mathrm{eV}$ and ( $\left.\mathrm{CF}_{3}-\mathrm{CF} 2-\right)$ at $292.3 \mathrm{eV}$. The electron beam exposure of the polymer reveals itself with increase in content of $\mathrm{CF}_{3}$ groups in the structure of the fluorocarbon layer. This indirectly indicates lower molecular weight of the coating as compared with the molecular weight of the initial polymer. The analysis of PTFE thin layers formed by electron-beam method is adequately held in [28].

The chemical composition of hydrocarbons was studied by decomposition of the $\mathrm{C} 1 \mathrm{~s}$ band on constituent separate peaks: at $283.3 \pm 0.1 \mathrm{eV}$ corresponding to $\mathrm{CH}_{3}$ group, at $284.1 \pm 0.1 \mathrm{eV}$ corresponding to $\mathrm{CH}_{2}$ group, at $284.4 \pm 0.1$ $\mathrm{eV}$ attributed to $\mathrm{C}-\mathrm{C}$ ( $\mathrm{SP}^{2}$ hybridization) / $\mathrm{C}-\mathrm{H}$ bonds, peak $285.3 \pm 0.1 \mathrm{eV}$ corresponding to $\mathrm{C}-\mathrm{C}\left(\mathrm{SP}^{3}\right)$ and $\mathrm{C}-\mathrm{H}$ bonds, at $285.6 \pm 0.1$ eVcorresponding to $(\mathrm{C}-\mathrm{N})$ bond, at $286,286.7 \pm 0.1$ corresponding to $-(\mathrm{C}-\mathrm{O})-$ groups, $288 \pm$ $0.1 \mathrm{eV}$ corresponding $\mathrm{C}=\mathrm{O}$ bonds [27, 29-33].

For comparison, the results of XPS analysis of the initial hydrocarbon powders are given. Paraffin surface layer is characterized by higher content of methyl groups as compared to the initial powder. Indirectly, this may be indicative of lower molecular weight of the surface coating layer of paraffin. The reverse phenomenon is observed in case of PE, for UHMW PE such changes in molecular structure are not so noticeable. For polymer-based coatings, in contrast to paraffin layer, the ratio of $\mathrm{C}-\mathrm{C}\left(\mathrm{SP}^{2}\right) / \mathrm{C}-\mathrm{H}$ / $\mathrm{C}-\mathrm{C}\left(\mathrm{SP}^{3}\right) / \mathrm{C}-\mathrm{H}$ is less than for initial compounds. The upper surface layer of polymer-based coatings contains fewer unsaturated bounds as compared to the original polymer. For paraffin thin layer and the initial powder such difference is almost negligible.

The results of XPS and IR studies are markedly different. This may be due to continuous change in composition of the dispersion products generated and, accordingly, in the composition of the coating throughout the thickness. Change in composition of the hydrocarbons destruction products is caused by chemical reactions in the electron flow impact zone.

The results of XPS analysis show the high content of oxygencontaining functional groups in thin layers based on PE. The 

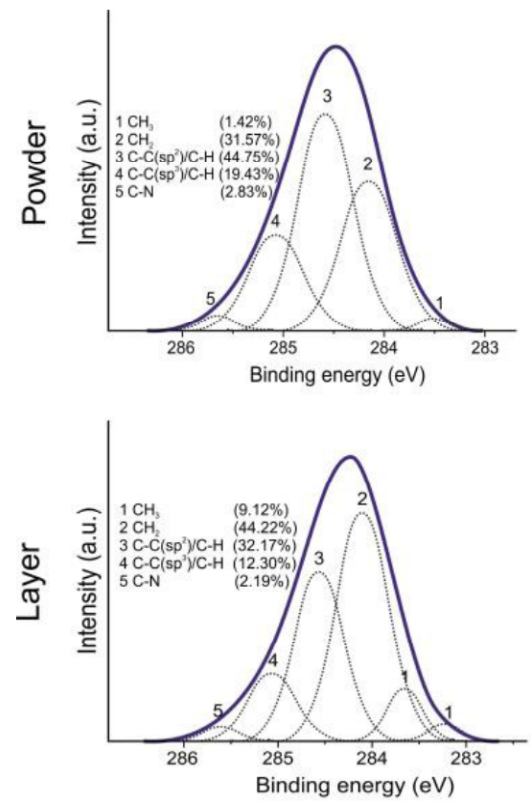

PARAFFIN
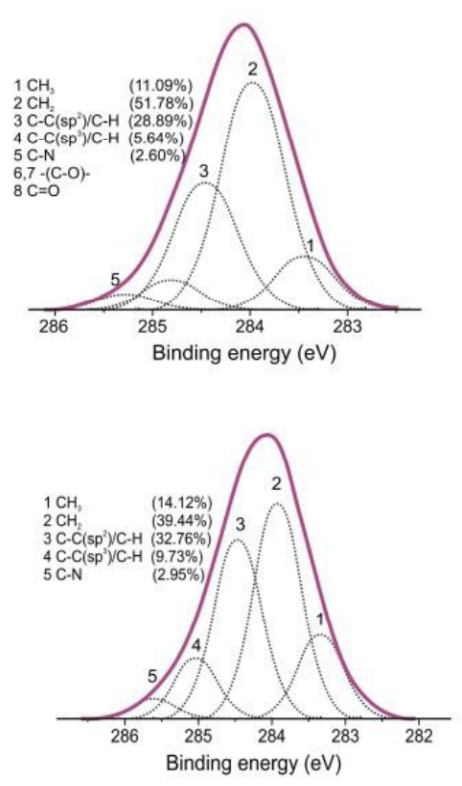

UHMWPE
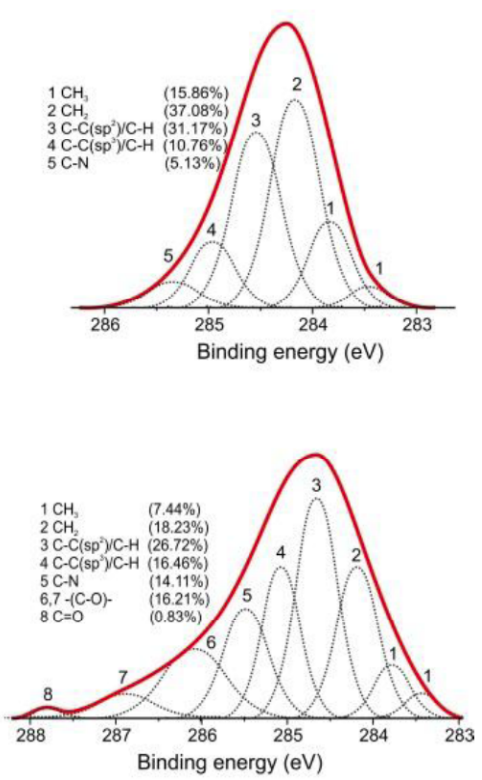

PE
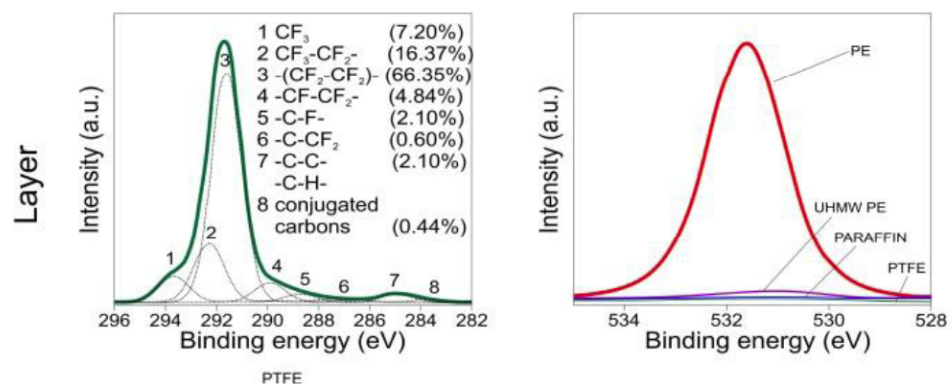

Figure 3: Results of XPS of thin coatings and initial materials.

appearance of oxygen-containing groups is caused by interaction of air oxygen with long-living radicals of the thin layer at depressurization of the vacuum chamber. The appearance of oxygen-containing groups is also possible in the process of reaction between atmospheric oxygen, atmospheric moisture and double unsaturated bonds. Among all hydrocarbon materials, PE molecules undergo the highest degree of destruction under exposure to electron beam. The XPS analysis determined the high content of $\mathrm{CH}_{3}$ groups in the coatings based on UHMW PE. The chemical composition of the coatings based on paraffin is least likely to undergo changes at exposure to electron beam.

\subsection{Measuring of Contact Angle}

It is determined that the nature of the hydrocarbon component has significant impact on the contact angle. Only composite coatings obtained by dispersing of paraffin and PTFE with high content of PTFE show superhydrophobic properties (Table 3, Figure $\mathbf{5}$ ).

It should be noted that relatively low values of the contact angle are peculiar for the coatings, the hydrocarbon component molecules of which contain more unsaturated bonds. PE-based coatings are characterized by the lowest values of the contact angle, which is expected taking into consideration the data of IR and XPS spectroscopy. High content of double unsaturated and oxygen-containing bonds in the molecular structure promotes reducing the magnitude of the contact angle.

It should be noted that based only on the data of IR spectroscopic studies, it is quite difficult to predict the magnitude of the contact angle. In particular, the problem of the impact of the substrate temperature on the magnitude of the contact angle would remain unclear. The substrate temperature is usually manifested in a change of unsaturation and crystallinity of the hydrocarbon layer and in increasing the defectiveness of the fluoroplastic component.

For paraffin - PTFE (1:6) coatings the hysteresis of the contact angle did not exceed $10^{\circ}\left(\sim 7^{\circ}\right)$. This shows that these coatings are superhydrophobic.

\subsection{Microscopic Analysis}

Studies of contact angle show that only thin composite layers based on PTFE and paraffin may be characterized by superhydrophobic properties. Therefore, exactly those 
Table 3: Results of Measuring of Contact Angle

\begin{tabular}{|c|c|c|c|c|c|c|}
\hline \multirow{3}{*}{$\begin{array}{l}\text { Temperature of the substrate } \\
\text { deposited, }{ }^{\circ} \mathrm{C}\end{array}$} & \multicolumn{6}{|c|}{ Contact angle, degrees } \\
\hline & \multicolumn{6}{|c|}{ weight ratio hydrocarbon: PTFE } \\
\hline & 1:0 & $1: 1$ & $1: 2$ & 1:4 & $1: 6$ & $0: 1$ \\
\hline \multicolumn{6}{|c|}{ paraffin } & \multirow{5}{*}{$\begin{array}{l}131 \\
131\end{array}$} \\
\hline 25 & 91 & 115 & 134 & 129 & 161 & \\
\hline 50 & 108 & 126 & 151 & 145 & 167 & \\
\hline \multicolumn{6}{|c|}{$\mathrm{PE}$} & \\
\hline 25 & 94 & 100 & 116 & 112 & 112 & \\
\hline 120 & 95 & 134 & 132 & 129 & 120 & \\
\hline \multicolumn{6}{|c|}{ UHMW PE } & \\
\hline 25 & 113 & 109 & 119 & 123 & 126 & \\
\hline 120 & 96 & 98 & 134 & 134 & 116 & \\
\hline
\end{tabular}

coatings were subjected to microscopic examinations, as well as paraffin and PTFE layers.

The coatings based on paraffin are characterized by smoothed morphology, lack of structure elements registered on coatings cross-sections. The heating of the substrate to the melting temperature contributes to additional smoothing of the hydrocarbon layer.

At high deposition rate, the fluorocarbon layer is formed by columnar formations, which, in turn, are formed by small spherical elements (Figure 4). Those elements may apparently be the result of interactions of fluorocarbon fragments in the gas phase. The low temperature of the substrate $\left(50^{\circ} \mathrm{C}\right)$ does not affect the morphology of the coating based on PTFE.

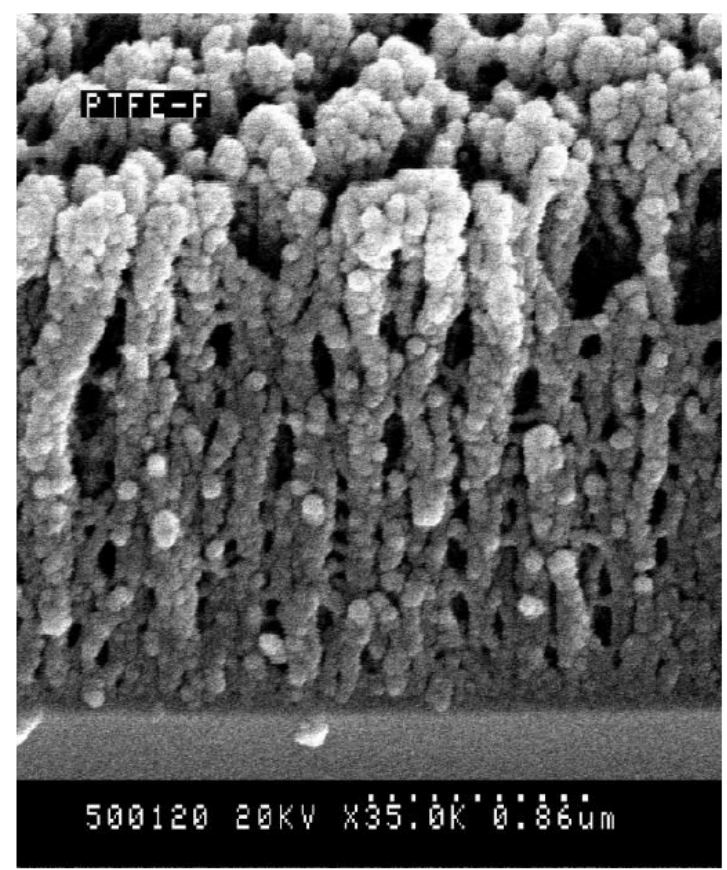

Figure 4: Cross-section morphology of PTFE-based coating.
The coatings deposited onto the substrate surface at room temperature by electron beam dispersion of powder mixture containing paraffin and PTFE have fine-grained, homogenous enough structure. With these formation conditions, the significant difference in physicochemical nature of the components deposited on the substrate, as well as in their generation rates, does not initiate phase layering. When deposited on the substrate heated to paraffin melting point, the hydrocarbon fragments form droplet formations, the size thereof decreases and the density increases if the portion of the fluoroplastic component increases (Figure 5). At the components ratio 1:6 in the mixture dispersed, hydrocarbon particles have the average diameter of less than $10 \mu \mathrm{m}$ and the height of greater than $5 \mu \mathrm{m}$. Fluorocarbon spherical formations of $\sim 1 \mu \mathrm{m}$ diameter are located on their surfaces. Such a structure resembles the surfaces of a lotus leaf.

\section{CONCLUSION}

The reaction activity of the products of electron beam dispersion of hydrocarbons sequentially decreases in the series of paraffin, PE, UHMWPE. Adding PTFE to hydrocarbon is followed by further significant decrease in reaction activity of gas phase dispersion products.

The molecular structure of hydrocarbon coatings formed is characterized by higher content of double unsaturated bonds vs. molecular structure of the initial hydrocarbon compound. Among all hydrocarbon material, paraffin molecules undergo the lowest degree of destruction under exposure to electron beam. The exposure of PTFE to electron beam is not followed by noticeable defluorination of fluorocarbon molecules.

Composite coatings may be regarded as fine-grained mechanical mixtures of modified initial components.

Composite coatings are characterized by fine-grained homogenous structure. The difference in physicochemical 

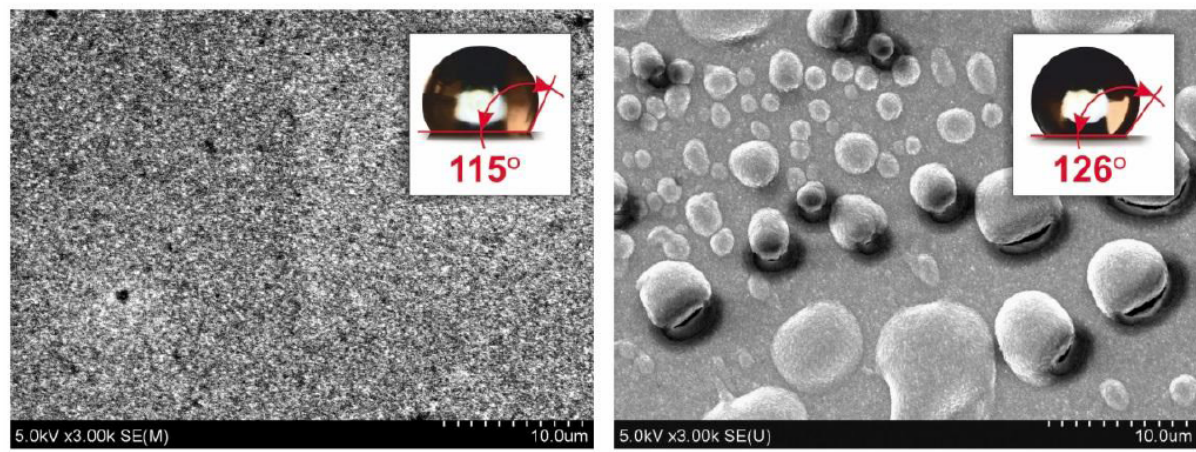

$1: 1$
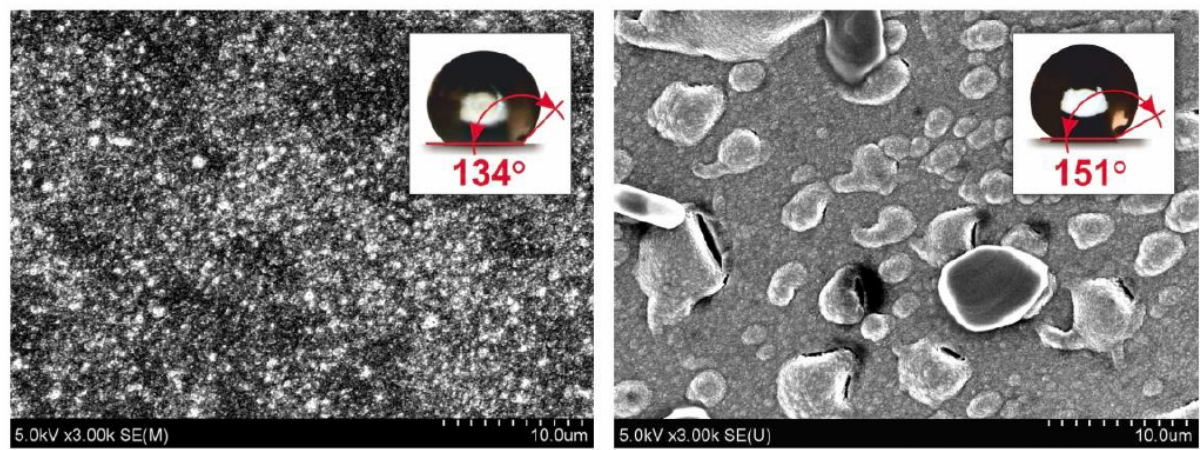

$1: 2$
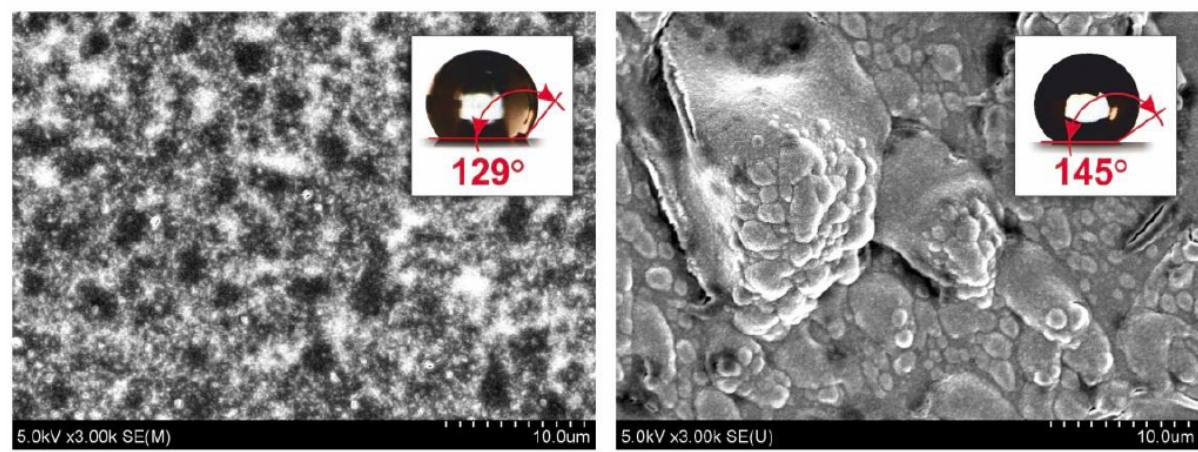

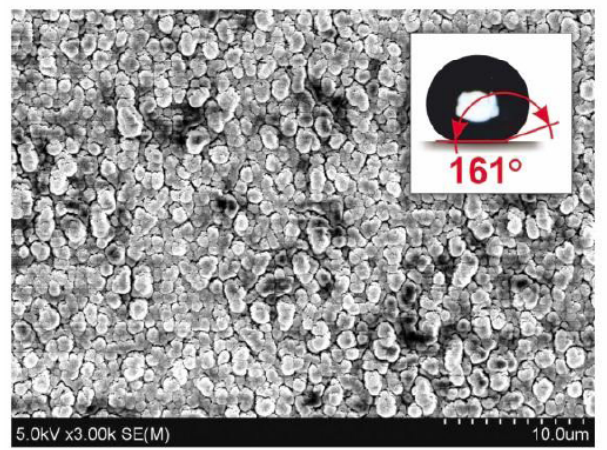

$25^{\circ} \mathrm{C}$

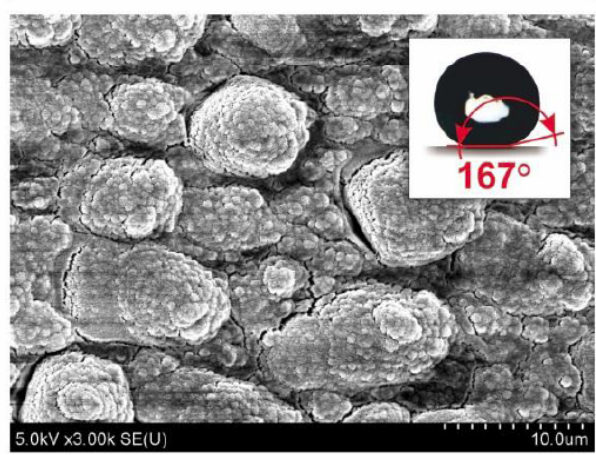

$50^{\circ} \mathrm{C}$

Figure 5: Morphology of paraffin and PTFE based coatings at different component ratios in the target and different temperature of the substrate deposited.

nature of the components deposited on the substrate, as well as in their generation rate, does not initiate phase separation. When deposited on the substrate heated to the hydrocarbon component melting temperature, hydrocarbon fragments form droplet formations, the size thereof decreases and the density increases when the portion of the fluoroplastic component increases. The composite coatings obtained by dispersing of paraffin and PTFE, with high content of PTFE, show superhydrophobic properties. The structure of such coatings is similar to the structure of the surface of a lotus leaf.

The preliminary studies of metal capillaries used in a biotechnological analyzer with a deposited PTFE-paraffin (6:1) composite layer displayed high effectiveness of the thin layer against the formation of microdroplets. Within a week of 
operation, the droplets on the surface of the working capillaries were not detected.

\section{REFERENCES}

[1] Guo Z, Liu W, Su B-L. Superhydrophobic surfaces: From natural to biomimetic to functional. J Colloid Interface Sci 2011; 353: 335-355. https://doi.org/10.1016/i.jcis.2010.08.047

[2] Ensikat HJ, Ditsche-Kuru P, Neinhuis C, Barthlott W. Superhydrophobicity in perfection: the outstanding properties of the lotus leaf. Beilstein J Nanotechnol 2011; 2: 152-161. https://doi.org/10.3762/bjnano.2.19

[3] Zhang P, Lv FY. Review of the recent advances in superhydrophobic surfaces and the emerging energy-related applications. Energy 2015; 82: 1068-1087. https://doi.org/10.1016/i.energy.2015.01.061

[4] Lima AC, Mano JF. Micro/nano-structured superhydrophobic surfaces in the biomedical field: part II: applications overview. Nanomedicine (Lond) 2015; 10: 271-297.

https://doi.org/10.2217/nnm.14.175

[5] Jeong H, Heo J, Son B, Choi D, Park TH, Chang M, Hong J. Intrinsic Hydrophobic Cairnlike Multilayer Films for Antibacterial Effect with Enhanced Durability. ACS Appl Mater Interfaces 2015; 7: 2611726123.

https://doi.org/10.1021/acsami.5b07613

[6] Cengiz U, Erbil HY. Superhydrophobic perfluoropolymer surfaces having heterogeneous roughness created by dip-coating from solutions containing anonsolvent. Appl Surf Sci 2014; 292: 591-597. https://doi.org/10.1016/i.apsusc.2013.12.013

[7] Heinonen S, Huttunen-Saarivirta E, Nikkanen JP, Raulio M, Priha O, Laakso J, Storgards E, Levanena E. Antibacterial properties and chemical stability of superhydrophobic silver-containing surface produced by sol-gel route. Colloids and Surfaces A: Physicochem Eng Aspects 2014; 453: 149-161.

https://doi.org/10.1016/j.colsurfa.2014.04.037

[8] Taurino R, Fabbri E, Pospiech D, Synytska A, Messoria M Preparation of scratch resistant superhydrophobic hybrid coatings by sol-gel process. Prog Org Coat 2014; 77: 1635-1641. https://doi.org/10.1016/i.porgcoat.2014.05.009

[9] Ovaskainen L, Chigome S, Birkin NA, Howdle SM, Torto N, Wagberg L, Turner C. Superhydrophobic polymeric coatings produced by rapid expansion of supercritical solutions combined with electrostatic deposition (RESS-ED). J of Supercritical Fluids 2014; 95: 610-617. https://doi.org/10.1016/i.supflu.2014.09.014

[10] Jeong BY, Jung EH, Kim JH. Fabrication of superhydrophobic niobium pentoxide thin films by anodization. Appl Surf Sci 2014; 307 : 28-32.

https://doi.org/10.1016/j.apsusc.2014.03.111

[11] Liang J, Liu K, Wang D, Li H, Li P, Li S, Su S, Xu S, Luo Y. Facile fabrication of super hydrophilic/superhydrophobic surface on titanium substrate by single-step anodization and fluorination. Appl Surf Sci 2015; 38: 126-136.

https://doi.org/10.1016/j.apsusc.2015.02.117

[12] Rezaei S, Manoucheri I, Moradian R, Pourabbas B. One-step chemical vapor deposition and modification of silica nanoparticles at the lowest possible temperature and superhydrophobic surface fabrication. Chem Eng J 2014; 252: 11-16. https://doi.org/10.1016/j.cej.2014.04.100

[13] Henry F, Renaux F, Coppee S, Lazzaroni R, Vandencasteele N, Reniers F, Snyders R. Synthesis of superhydrophobic PTFE-like thin films by self-nanostructuration in a hybrid plasma process. Surface Science 2012; 606: 1825-1829. https://doi.org/10.1016/j.susc.2012.07.025

[14] Jafari R, Menini R, Farzaneh M. Superhydrophobic and icephobic surfaces prepared by RF-sputtered polytetrafluoroethylene coatings. Appl Surf Sci 2012; 259: 719-725.

[15] Kim HK, Cho YS. Fabrication of a superhydrophobic surface via spraying withpolystyrene and multi-walled carbon nanotubes. Colloids Surf A: Physicochem Eng Asp 2015; 465: 77-86. https://doi.org/10.1016/i.colsurfa.2014.10.029

[16] Gong D, Long J, Fan P, Jiang D, Zhang H, Zhong M. Thermal stability of micro-nanostructures and superhydrophobicity of polytetrafluoroethylene films formed by hot embossing via apicosecond laser ablated template. Appl Surf Sci 2015; 331: 437 443. https://doi.org/10.1016/j.apsusc.2015.01.102

[17] Duan Z, Zhao Z, Luo D, Zhao M, Zhao G. A facial approach combining photosensitive sol-gel with self-assembly method to fabricate superhydrophobic $\mathrm{TiO}_{2}$ films with patterned surface structure. Appl Surf Sci 2016; 360: 1030-1035. https://doi.org/10.1016/i.apsusc.2015.11.114

[18] $\mathrm{Li}$ Z. Hierarchical $\mathrm{ZnO}$ films with microplate/nanohole structures induced by precursor concentration and colloidal templates, their superhydrophobicity, and enhanced photocatalytic performance. Mater Res 2014; 29: 115-122. https://doi.org/10.1557/imr.2013.182

[19] Ragachev AV, Yarmolenko MA, Rogachev AA, Gorbachev DL, Zhou B. Chemical composition morphology and optical properties of zinc sulfide coatings deposited by low-energy electron beam evaporation. Appl Surf Sci 2014; 303: 23-29. https://doi.org/10.1016/i.apsusc.2014.02.030

[20] Rogachev AA, Yarmolenko MA, Rogachou AV, Tapalski DV, Liu X Gorbachev DL. Morphology and structure of antibacterial nanocomposite organic-polymer and metal-polymer coatings deposited from active gas phase. RSC Adv 2013; 3: 11226-11233. https://doi.org/10.1039/c3ra23284k

[21] Liu Z, Zhou B, Rogachev AV, Yarmolenko MA. Growth feature of PTFE coatings on rubber substrate by low-energy electron beam dispersion. Polym Adv Technol 2016; 27: 823-829.

https://doi.org/10.1002/pat.3723

[22] Liu Z, Zhou B, Rogachev AV, Yarmolenko MA. Structure and tribological properties of Cu-PU-PTFE composite coatings prepared by low-energy electron beam dispersion with glow discharge. Polym Adv Technol 2016.

https://doi.org/10.1002/pat.3821

[23] Crystalline Olefin Polymers. Raff RAV, Doak KW, Eds. Published by Interscience Publishers, John Wiley 1965

[24] Dechant J, Danz R, Kimmer V, Schmolke R. Infra krasnaya spektroskopiya polimerov (Infrared Spectroscopy of Polymers). Moscow, 1976; p. 472.

[25] Gritsenko KP, Krasovsky AM. Thin-Film Deposition of Polymers by Vacuum Degradation. Chem Rev 2003; 103: 3607-3649. https://doi.org/10.1021/cr010449q

[26] Laguardia L, Ricci D, Vassallo E, Cremona A, Mesto E, Grezzi F Dellera F. Deposition of Super-Hydrophobic and Oleophobic Fluorocarbon Films in Radio Frequency Glow Discharges. Macromo Symp 2007; 247: 295-302. https://doi.org/10.1002/masy.200750133

[27] Teodoru S, Kusano Y, Rozlosnik N, Michelsen PK. Continuous Plasma Treatment of Ultra-High-Molecular-Weight Polyethylene (UHMW PE) Fibres for Adhesion Improvement. Plasma Process Polym 2009; 6: 375-381. https://doi.org/10.1002/ppap.200930906

[28] Rubahn HG, et al. Interface Controlled Organic Thin Films, Book Springer Proceedings in Physics, 2009; vol. 129.

[29] Park SJ, Song SY, Shin JS, Rhee JM. Effect of surface oxyfluorination on the dyeability of polyethylene film. J Colloid Interface Sci 2005; 283: 190-195 https://doi.org/10.1016/j.jcis.2004.02.094

[30] Marcondes AR, Ueda M, Kostov KG, Beloto AF, Leite NF, Gomes GF Lepienski CM. Improvements of Ultra-High Molecular Weight Polyethylene Mechanical Properties by Nitrogen Plasma Immersion Ion Implantation. Brazilian Journal of Physics 2004; 34: 1667-1672. https://doi.org/10.1590/S0103-97332004000800029

[31] Weckhuysen BM, Rosynek MP, Lunsford JH. Characterization of surface carbon formed during the conversion of methane to benzene over Mo/H-ZSM-5 catalysts. Catalysis Letters 1998; 52: 31-36. https://doi.org/10.1023/A:1019094630691

[32] Van Deynse A, Cools P, Leys C, De Geyter N, Morent R. Surface activation of polyethylene with an argon atmospheric pressure plasma jet: Influence of applied power and flow rate. Appl Surf Sci 2015; 328: 269-278.

https://doi.org/10.1016/j.apsusc.2014.12.075

[33] Turgeon S, Paynter RW. On determination of carbon $\mathrm{sp}^{2} / \mathrm{sp}^{3}$ ratios in polystyrene-polyethylene copolymers by photoelectron spectroscopy. Thin Solid Films 2004; 394: 44-48. 